\title{
Editorial
}

\section{People-centred health care: A good idea but difficult to implement}

journal homepage: http://www.elsevier.com/locate/kontakt

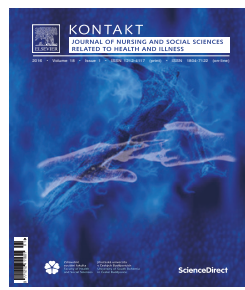

\author{
Jiří Mareš * \\ Charles University, Faculty of Medicine in Hradec Králové, Czech Republic
}

We are used to the fact that many branches of medicine focus on disease, its aetiology, diagnostics and treatment. They also try to prevent diseases and move the population towards a healthy lifestyle. If people are already ill, they lead them to follow doctors' instructions and actively participate in treatment. Professionals have created recommended guidelines, which guarantee that medical treatment will be according to the law of the art. However we are not aware of the fact that this approach accents disease itself and particularly weakens the interest in individuality of the ill. In many cases the person in front of us remains an impersonal patient with a certain diagnosis.

No wonder there gradually grew voices that said that this concept is not enough; it is necessary to much more consider the particularities of people with a particular disease. It is necessary to consider not only the biological, but also the psychological and social aspects of our patients. The approach accenting the particularities of patients has gradually gained followers and reached the phase that was metaphorically named by Tinetti and Fried [1]: "The end of the era of a disease." The change of orientation of health care from a disease to a patient did not occur suddenly, it has been prepared for tens of years.

At first the most used term was "person-centred care" (PCC) or its option person-centred health care (PCHC). While implementing this term, the health service was inspired by publications of an American humanistic psychologist Carl Rogers [2] who came up with a concept called "person-centred therapy".

Some experts of the history of health service go even further back, and remind us of the founder of professional nursing, Florence Nightingale, who said that what distinguishes nursing from medicine is the focus on a patient rather than on a disease [3, p. 246]. The term $a$ person is perceived within the meaning of an individual and individuality here.

Considering the health context, the common term a person, an individual has been further specified to the term a patient. Some authors do not limit the term "a patient" to an ill man or a man with health problems who seeks a health care facility, it can also include a man with some unsatisfied needs. A patient can even be a family as a whole, a social group, a community [3]. While searching for the historical roots of this concept, the researchers found out that already in 1967 a theoretician of nursing, M. E. Levine, came up with a term "patient-centred care" [4]. Approximately at the same time as she published her nursing concept, another concept focused on the medical aspect and work of doctors appeared within professional literature. It was the wife of a known doctor Michael Balint - Enid Balint [5] who wrote about the topic of how a doctor should deal with a patient in order to better understand their problems. She stated that a traditional approach is an illness-oriented medicine but there exists also another approach: a patient centred medicine. It perceives a patient as a whole, as a unique human being and tries to set their "overall" diagnoses.

Thereafter, these efforts were moved over and the mentioned ideas were "rediscovered" at the end of the 1980s. Surprisingly these were not health professionals who returned to these efforts but a layman: the American inventor, entrepreneur, lecturer and philanthropist Harvey Picker (1915-2008) who did not like that the American health care system is very good considering its technical and technological aspects, however it does not consider

\footnotetext{
* Korespondenční autor: Prof. PhDr. Jiří Mareš, CSc., Charles University, Faculty of Medicine in Hradec Králové, Czech Republic; email: mares@lfhk.cuni.cz

http://dx.doi.org/10.1016/j.kontakt.2017.02.001
} 
patients' needs very much. Therefore, in 1986 he founded an institute that has bore his name (Picker Institute) up to now, and he started to promote patient-centred care. His aim was to extend this type of care to hospitals and health facilities of primary care. He also promoted the said programme with the writing and publishing of a book that examined various dimensions of patient-centred care. The book had a characteristic title: Through the patient's eyes: understanding and promoting patient-centred care [6].

The basic principles of patient-centred care can be formulated as follows [7]:

1. Fast access to reliable healthcare advice.

2. Effective treatment delivered by trusted professionals.

3. Continuity of care and smooth transitions.

4. Involvement of, and support for, family and carers.

5. Clear, comprehensible information and support for self-care.

6. Involvement in decisions and respect for patient's preferences.

7. Emotional support, empathy and respect.

8. Attention to physical and environmental needs.

A longtime experience of medical staff confirms that the care of a patient is not only patient's matter but it is influenced by the attitude and behaviour of their family members. It is therefore logical that a reflection on (especially in children and teenagers) the individualization of provided care widened and includes also their families. A new approach and a new term have appeared: patientand family-centred care. This concept has been developed by the Institute for patient-and family-centred care that was founded in 1992 and is domiciled in Bethesda, USA [8].

This was followed by a term with wider meaning which is health care centred on people, on population (people-centred care). This direction of ideas started to be more carefully formulated only in the last 15 years. It is recommended in WHO documents $[9,10]$ and getting a form of health services centred on people, on the population. What does this term mean? "People-centred health services are an approach to care that consciously adopts the perspectives of individuals, families and communities, and sees them as participants as well as beneficiaries of trusted health systems that respond to their needs and preferences in humane and holistic ways. It requires that people have the education and support they need to make decisions and participate in their own care. It is organised around the health needs and expectations of people rather than diseases" [10, p. 11].

Another important institution elaborating this attitude and trying to implement it into usual health practice is the International College of Person-Centred Medicine that was founded in 2009 in New York. Its conferences gradually dealt with the care of chronically ill patients [11], health research in this specific field [12], integrated health care for everybody [13], primary health care [14] and care centred on a persons throughout their lives [15].

While implementing this attitude to health care facilities many barriers appear that are still difficult to overcome. Let us look at five examples (of various levels of commonness and seriousness):
- Organisational barriers: ... "Currently, patient centred care is often hindered by the traditional division of services between different sectors and organisations, each with its own systems, performance measures, funding approaches, commissioners and cultures" [16, p. 17].

- Payment by results: ... "By paying for each episode of care, it reinforces a disease focused approach, while doing nothing to incentivize providers to prevent or delay the onset of illness or to find alternatives to hospital admissions. In addition, the system inhibits collaboration between providers, encouraging organisational behaviours and responses that are driven by the desire to maximise income and minimise costs, rather than to work collaboratively to deliver patient centred care" [16, p. 17].

- Physician workload. ... "Physicians need to be involved in person-centred care planning and implementation at some level, despite their heavy clinical demands and time constraints. A well-coordinated interprofessional team can help to distribute the significant workload involved in managing the complex care of chronically ill older adults while bringing valuable perspectives and skills to person-centred care delivery" [17, p. 17].

- Identifying appropriate indicators: ... "Measures such as blood pressure and glycosylated haemoglobin are easy to obtain but do not measure person-centred outcomes. Quality indicators need to be defined for person-centred care... with complex conditions or multiple comorbidities" [17, p. 17].

- Slow progress on information systems: ... "The absence of a robust shared electronic patient record, that can be used by all those involved in the care of a particular individual (including across different organisations and by the individual themselves), is... a major barrier to developing a more appropriate and integrated response to people's needs" [16, p. 18].

Summary: a patient-centred attitude is a promising tendency in the improvement of health care not only at the level of an individual and a family, but also at the level of a community and a state. It does not seem that this tendency is a total contrast to ill-centred care. It is a part of this care improving it with seriously perceived individualization of care, an individualization which has been rather only proclaimed than widely used. However, its integrating in clinical practise interferes with psychological, organizational, technical and even economical limits of the existing form of medical systems and the common ways of their functioning.

\section{REFERENCES}

[1] Tinetti ME, Fried T. The end of the disease era. Am J Med 2004;116(3):179-85.

[2] Rogers CR. Significant aspects of client centered therapy. Am Psychol 1946;1(10):415-22.

[3] Lauver DR, Ward SE, Heidrich SM, Keller ML, Bowers BJ, Brennan PF et al. Patient-centered interventions. Res Nurs Health 2002;25(4):246-55. 
[4] Levine ME. This I believe: about patient centered care. Nurs Outlook 1967;15(4):53-5.

[5] Balint E. The possibilities of patient-centred medicine. J R Coll Gen Pract 1969;17(82):269-76.

[6] Gerteis M, Edgman-Levitan S, Daley J, Delbanco TL (Eds). Through the patient's eyes: understanding and promoting patient-centered care. San Francisco: JosseyBass; 1993.

[7] Picker Institute Europe. Principles of patient-centred care. [online] [cit. 2017-02-28]. Available from: http:// www.pickereurope.org/about-us/principles-of-patientcentred-care/

[8] Institute for patient- and family-centered care. Transforming health care through partnerships. Bethesda; 2017. [online] [cit. 2017-02-28]. Available from: http://www.ipfcc.org/about/index.html

[9] World Health Organization. People-centred health care: a policy framework. Manila: World Health Organization; 2007.

[10] World Health Organization. WHO global strategy on people-centred and integrated health services: Interim report. Geneva: World Health Organization; 2015.
[11] Geneva declaration on person-centered care for chronic diseases. Geneva: International College of PersonCentered Medicine; 2012.

[12] Geneva declaration on person-centered care of health research. Geneva: International College of PersonCentered Medicine; 2013.

[13] Geneva declaration on person- and people-centered integrated health care. Geneva: International College of Person-Centered Medicine; 2014.

[14] Geneva declaration on person-centered primary health care. Geneva: International College of Person-Centered Medicine; 2015.

[15] Geneva declaration on person-centered integrated care though the life course. Geneva: International College of Person-Centered Medicine; 2016.

[16] Royal College of General Practitioners: An inquiry into patient centred care in the 21st century. Implications for general practice and primary care. London: Royal College of General Practitioners; 2014.

[17] American Geriatrics Society. Person-centered care: a definition and essential elements. J Am Geriatr Soc. 2016;64(1):15-18. 